Pacific Journal of Mathematics

THE DEGREE OF MONOTONE APPROXIMATION 


\title{
THE DEGREE OF MONOTONE APPROXIMATION
}

\author{
R. K. BEATSON
}

Jackson type theorems are obtained for generalized monotone approximation. Let $E_{n, k}(f)$ be the degree of approximation of $f$ by $n$th degree polynomials with $k$ th derivative nonnegative on $[-1 / 4,1 / 4]$. Then for each $k \geqq 2$ there exists an absolute constant $D_{k}$, such that for all $f \in C[-1 / 4,1 / 4]$ with $k$ th difference nonnegative on $[-1 / 4,1 / 4] ; E_{n, k}(f) \leqq D_{k} \omega\left(f, n^{-1}\right)$. If in addition $f^{\prime} \in C[-1 / 4,1 / 4]$ then $E_{n, k}(f) \leqq D_{k} n^{-1} \omega\left(f^{\prime}, n^{-1}\right)$.

Given a function $f$ with nonnegative $k$ th difference on $[-1 / 4,1 / 4]$ (equivalently any finite real interval) it is natural to ask whether Jackson type estimates hold for

$$
E_{n, k}(f)\left\|_{\left\{p \in \Pi_{n}: p^{(k)}\right.} \inf _{(x) \geq 0, x \in[-1 / 4,1 / 4]\}}\right\| f-p \|:
$$

where the norm is the uniform norm, and $\Pi_{n}$ is the space of algebraic polynomials of degree not exceeding $n$. In the case $k=1$, Lorentz and Zeller [4] and Lorentz [5] have shown that there exists a constant $D_{1}$ such that if $f$ is increasing on $[-1 / 4,1 / 4]$

$$
E_{n, 1}(f) \leqq D_{1} \omega\left(f, n^{-1}\right),
$$$$
n=1,2, \cdots,
$$

where $\omega(f, \cdot)$ denotes the modulus of continuity of $f$. If, in addition, $f^{\prime} \in C[1 / 4,14]$ then

$$
E_{n, 1}(f) \leqq D_{1} n^{-1} \omega\left(f^{\prime}, n^{-1}\right), \quad n=1,2, \cdots .
$$

DeVore [2,3] has given a much simpler proof of the $k=1$ results. The results of this paper are obtained with similar arguments.

Notation. Throughout $C_{1}, C_{2}, \cdots$ denote positive constants depending on $k$, but not depending on $f, x$ or $n \geqq k$. Whenever it causes no confusion, $\|\cdot\|_{\beta}$ denotes $\|\cdot\|_{[-\beta, \beta]}$ and $\omega(e, \cdot)$ denotes $\omega_{[-1 / 4,1 / 4]}(e, \cdot)$.

A function with nonnegative $k$ th difference on $[a, b]$ cannot, in general, be extended to a function with nonnegative $k$ th difference on a larger interval. For example the piecewise linear and convex function, $f \in C\left[0, \sum_{n=1}^{\infty} n^{-3}\right]$, with slope $n$ on the interval

$$
\left[\sum_{i=1}^{n-1} i^{-3}, \sum_{i=1}^{n} i^{-3}\right] \text {, }
$$

cannot be extended to the right and remain convex. This motivates the construction of a preapproximation (see Lemma 1) to $f$, to which 
we will apply appropriate polynomial convolution operators (see Lemma 2).

Lemma 1 . Suppose $k \geqq 2$. Let

$$
L_{n}(h, x)=(2 \lambda)^{-k} \int_{-\lambda}^{\lambda} \cdots \int_{-\lambda}^{\lambda} h\left(x+t_{1}+\cdots+t_{k}\right) d t_{1} \cdots d t_{k}
$$

where $h \in C[-1 / 4,1 / 4]$ and

$$
\lambda=1 / 8 n, \quad n=k, k+1, \cdots .
$$

Extend the definition of $L_{n}(h)$ from

$$
[-\alpha, \alpha]=\left[-\frac{1}{4}+\frac{k}{8 n}, \frac{1}{4}-\frac{k}{8 n}\right]
$$

to $[-1 / 2,1 / 2]$ by adjoining, to the right and left the Taylor polynomials of degree $k$, corresponding to $L_{n}(h)$ at the points $\alpha,-\alpha$. Then there exists constants $E_{k}, F_{k}, G_{k} ; \bar{E}_{k}, \bar{F}_{k}, \bar{G}_{k}$; such that; for all $f \in C[-1 / 4,1 / 4]$ with $f(-1 / 4)=f(1 / 4)=0$ and nonnegative kth difference on $[-1 / 4,1 / 4]$; for $n=k, k+1, \cdots$;

$$
L_{n}(f, x)^{(k)} \geqq 0, \quad x \in R,
$$

and

$$
\left\|L_{n}(f)\right\|_{1 / 4} \leqq G_{k} n \omega\left(f, n^{-1}\right) \text {. }
$$

If in addition $f^{\prime} \in C[-1 / 4,1 / 4]$ then

$$
\begin{aligned}
\left\|L_{n}(f)^{(j)}\right\|_{1 / 4} & \leqq \bar{E}_{k} n^{j-1} \omega\left(f^{\prime}, n^{-1}\right) \quad(j=2, \cdots, k-1), \\
\left\|L_{n}(f)^{(k)}\right\|_{1 / 2} & \leqq \bar{E}_{k} n^{k-1} \omega\left(f^{\prime}, n^{-1}\right), \\
\left\|f-L_{n}(f)\right\|_{1 / 4} & \leqq \bar{F}_{k} n^{-1} \omega\left(f^{\prime}, n^{-1}\right),
\end{aligned}
$$

and

$$
\left\|L_{n}(f)^{(2-j)}\right\|_{1 / 4} \leqq \bar{G}_{k} n \omega\left(f^{\prime}, n^{-1}\right) . \quad(j=1,2)
$$

Proof. For $x \in[-\alpha, \alpha]$

$$
L_{n}(f, x)=(2 \lambda)^{-k} \int_{-\lambda}^{\lambda} \cdots \int_{-\lambda}^{\lambda} \int_{x+t_{2}+\cdots+t_{k}-\lambda}^{x+t_{2}+\cdots+t_{k}+\lambda} f(\gamma) d \gamma d t_{2} \cdots d t_{k}
$$

implying 


$$
L_{n}(f, x)^{\prime}=(2 \lambda)^{-k} \int_{-\lambda}^{\lambda} \cdots \int_{-\lambda}^{\lambda} \Delta_{2 \lambda} f\left(x+t_{2}+\cdots+t_{k}-\lambda\right) d t_{2} \cdots d t_{k} ;
$$

repeating the argument, $j$ times, $j=1, \cdots k$,

$$
\begin{aligned}
& L_{n}(f, x)^{(j)} \\
& \quad=(2 \lambda)^{-k} \int_{-\lambda}^{\lambda} \cdots \int_{-\lambda}^{\lambda} \Delta_{2 \lambda}^{j} f\left(x+t_{j+1}+\cdots+t_{k}-j \lambda\right) d t_{j+1} \cdots d t_{k} .
\end{aligned}
$$

(5) follows immediately. (10) and the definition of $\lambda$ imply

$$
\left\|L_{n}(f)^{(j)}\right\|_{\alpha} \leqq C_{1} n^{j} \omega\left(f, n^{-1}\right) \quad(j=1, \cdots, k) .
$$

(6), (7) follow from (11) on estimating the derivatives of the Taylor polynomials extending $L_{n}(f)$ to the larger interval.

To prove (8). The definition of $L_{n}(f, x)$ clearly implies

$$
\left\|f-L_{n}(f)\right\|_{\alpha} \leqq C_{2} \omega\left(f, n^{-1}\right) \text {. }
$$

Also

$$
\begin{aligned}
\left\|f-L_{n}(f)\right\|_{[\alpha, 1 / 4]} \leqq & \|f-f(\alpha)\|_{[\alpha, 1 / 4]}+\left|f(\alpha)-L_{n}(f, \alpha)\right| \\
& +\left\|L_{n}(f)-L_{n}(f, \alpha)\right\|_{[\alpha, 1 / 4]}
\end{aligned}
$$

so by (4); (12); (6), (7); and the manner in which $L_{n}(f)$ was extended

$$
\left\|f-L_{n}(f)\right\|_{[\alpha, 1 / 4]} \leqq C_{3} \omega\left(f, n^{-1}\right) .
$$

A similar result holds on $[-1 / 4,-\alpha]$; (8) follows.

To prove (9). Note that (8) implies both

$$
\omega\left(L_{n}(f), n^{-1}\right) \leqq C_{4} \omega\left(f, n^{-1}\right)
$$

and

$$
L_{n}(f,-1 / 4) \leqq F_{k} \omega\left(f, n^{-1}\right) ;
$$

the second since $f(-1 / 4)=0$; (9) follows.

We proceed to prove the results for $f^{\prime} \in C[-1 / 4,1 / 4]$. Arguments analogous to those leading from (10) to (6), (7); lead from

$$
\begin{aligned}
& L_{n}(f, x)^{(j)} \\
& \quad=(2 \lambda)^{-k} \int_{-\lambda}^{\lambda} \cdots \int_{-\lambda}^{\lambda} \Delta_{2 \lambda}^{j-1} f^{\prime}\left(x+t_{j}+\cdots+t_{k}-(j-1) \lambda\right) d t_{j} \cdots d t_{k}, \\
& (j=1, \cdots, k) \text { to }\left(6^{\prime}\right),\left(7^{\prime}\right) .
\end{aligned}
$$

To show $\left(8^{\prime}\right)$ we use the quantitative Korovkin type estimate (see e.g., DeVore [2, p. 28-32]) 
(13)

$$
\begin{aligned}
\left|L_{n}(f, x)-f(x)\right| \leqq & |f(x)|\left|1-L_{n}(1, x)\right|+\left|f^{\prime}(x)\right|\left|L_{n}((t-x) . x)\right| \\
& +\left(1+\sqrt{L_{n}(1, x)}\right) \alpha_{n}(x) \omega\left(f^{\prime}, \alpha_{n}(x)\right)
\end{aligned}
$$

where

$$
\alpha_{n}^{2}(x)=L_{n}\left((t-x)^{2}, x\right) .
$$

Now $\left\|1-L_{n}(1)\right\|=\left\|L_{n}((t-x), x)\right\|=0$, while

$$
\begin{aligned}
L_{n}\left((t-x)^{2}, x\right) & =(2 \lambda)^{-k} \int_{-\lambda}^{\lambda} \cdots \int_{-\lambda}^{\lambda}\left(t_{1}+t_{2}+\cdots+t_{k}\right)^{2} d t_{1} \cdots d t_{k} \\
& =k(2 \lambda)^{-1} \int_{-\lambda}^{\lambda} t^{2} d t \leqq C_{5} \cdot n^{-2}
\end{aligned}
$$

Substituting into (13), (14) we find

$$
\left\|L_{n}(f)-f\right\|_{\alpha} \leqq C_{6} n^{-1} \omega\left(f^{\prime}, n^{-1}\right) .
$$

Since for this particular operator

$$
L_{n}(f, x)^{\prime}=L_{n}\left(f^{\prime}, x\right), \quad x \in[-\alpha, \alpha]
$$

and $L_{n}(f, x)^{\prime}$ is continued outside $[-\alpha, \alpha]$ by adjoining the Taylor polynomials of degree $k-1$, corresponding to $f^{\prime}$, at either end point; reasoning, similar to that yielding (8), implies

$$
\left\|f^{\prime}-L_{n}(f)^{\prime}\right\|_{1 / 4} \leqq C_{7} \omega\left(f^{\prime}, n^{-1}\right) \text {. }
$$

Writing

$$
\left\|f-L_{n}(f)\right\|_{[\alpha, 1 / 4]} \leqq\left|f(\alpha)-L_{n}(f, \alpha)\right|+\int_{\alpha}^{1 / 4}\left|f^{\prime}(t)-L_{n}(f, t)^{\prime}\right| d t ;
$$

$(12 ') ;(4)$ and (15) imply

$$
\left\|f-L_{n}(f)\right\|_{[\alpha, 1 / 4]} \leqq C_{8} n^{-1} \omega\left(f^{\prime}, n^{-1}\right) .
$$

Combining the above, the similar result on $[-1 / 4,-\alpha]$, and $\left(12^{\prime}\right)$ proves $\left(8^{\prime}\right)$.

To show $\left(9^{\prime}\right)$. Note (15) implies

$$
\omega\left(L_{n}(f)^{\prime}, n^{-1}\right) \leqq C_{9} \omega\left(f^{\prime}, n^{-1}\right)
$$

and also

$$
\left|L_{n}(f, \xi)^{\prime}\right| \leqq C_{7} \omega\left(f^{\prime}, n^{-1}\right) \quad \text { where } \quad f^{\prime}(\xi)=0,-\frac{1}{4}<\xi<\frac{1}{4} ;
$$

the existence of such an $\xi$ following from $f(-1 / 4)=f(1 / 4)=0$. Hence 


$$
\left\|L_{n}(f)^{\prime}\right\|_{1 / 4} \leqq C_{10} n \omega\left(f^{\prime}, n^{-1}\right) .
$$

$\left(9^{\prime}\right)$ follows since $\left(8^{\prime}\right)$ implies

$$
\left|L_{n}\left(f,-\frac{1}{4}\right)\right| \leqq \bar{F}_{k} n^{-1} \omega\left(f^{\prime}, n^{-1}\right) .
$$

We now know how well $L_{n}(f)$ approximates $f$, and concern ourselves with how well $L_{n}(f)$ may be approximated by convolutions with positive polynomials.

Lemma 2. Suppose $k \geqq 2$. Then there exist constants $H_{k}, I_{k}$ and a sequence of even positive algebraic polynomials $\left\{\lambda_{n}\right\}_{n=k}^{\infty}$ satisfying

$$
\int_{-1}^{1} \lambda_{n}(t) d t=1
$$

and

$$
\begin{aligned}
\left\|\lambda_{n}^{(j)}\right\|_{[-1,1][-1 / 4,1 / 4]} \leqq H_{k} n^{2-4 k+2 j}\left(\leqq H_{k} n^{-2 k}\right) & \\
& (j=0, \cdots, k-1) .
\end{aligned}
$$

Further if $f$ satisfies the conditions of Lemma $1, g=L_{n}(f)$ and

$$
L_{n}^{*}(g)=\int_{-1 / 2}^{1 / 2} g(t) \lambda_{n}(t-x) d t ;
$$

then if $f \in C[-1 / 4,1 / 4]$

$$
\left\|g-L_{n}^{*}(g)\right\|_{1 / 4} \leqq I_{k} \omega\left(f, n^{-1}\right) ;
$$

and if $f^{\prime} \in C[-1 / 4,1 / 4]$

$$
\left\|g-L_{n}^{*}(g)\right\|_{1 / 4} \leqq I_{k} n^{-1} \omega\left(f^{\prime}, n^{-1}\right) .
$$

Proof. Let $\lambda_{k}=\lambda_{k+1}=\cdots=\lambda_{4 k-1} \equiv 1 / 2$. For $n \geqq 2 k$, let

$$
\lambda_{4 n-4 k}(t)=c_{n}\left[P_{2 n}(t) /\left(\left(t^{2}-x_{1,2 n}^{2}\right) \cdots\left(t^{2}-x_{k, 2 n}^{2}\right)\right)\right]^{2},
$$

where $P_{2 n}$ is the Legendre polynomial of degree $2 n$ and $x_{1,2 n}, \cdots, x_{n, 2 n}$ are its positive zeros in increasing order. $c_{n}$ is a normalizing constant for (16). Define the remaining $\lambda_{n}$ 's with the relation

$$
\lambda_{4 n+1}=\lambda_{4 n+2}=\lambda_{4 n+3}=\lambda_{4 n}, \quad n \geqq k .
$$

Observe firstly that a theorem of Bruns (see e.g., DeVore [2, p. 20]) implies

$$
C_{11} n^{-1} \leqq x_{1,2 n}<\cdots<x_{k, 2 n} \leqq C_{12} n^{-1}, \quad n>k
$$

Using the normalization $\left\|P_{n}\right\|_{[-1,1]}=1$ and the corresponding Taylor 
expansion of $P_{n}$ (see e.g., Davis [1, p. 365]),

$$
\left|P_{2 n}(0)\right|=2^{-2 n}\left[\begin{array}{c}
2 n \\
n
\end{array}\right]=(1+o(1)) / \sqrt{\pi n},
$$

the last equality being a consequence of Stirlings formula. and (23) together imply

$$
\lambda_{4 n-4 k}(0) \geqq C_{13} c_{n} n^{4 k-1}, \quad n \geqq 2 k .
$$

Let $n \geqq 2 k$. Write

$$
1=\int_{-1}^{1} \lambda_{4 n-4 k}(t) d t=\sum_{k=-n}^{n} A_{k}(2 n+1) \lambda_{4 n-4 k}\left(x_{k, 2 n+1}\right) ;
$$

where the $A_{k}(2 n+1)$ are the weights of the Gaussian quadrature formula, exact for polynomials of degree $4 n+1$, with nodes at the zeros of the Legendre polynomial of degree $2 n+1$. Therefore

$$
1 \geqq A_{0}(2 n+1) \lambda_{4 n-4 k}(0)
$$

and since (Szego $\left[6\right.$, p. 350]), $A_{0}(2 n+1)=\pi(1+o(1)) /(2 n+1)$

$$
\lambda_{4 n-4 k}(0) \leqq C_{14} n \text {. }
$$

(24) and (25) imply

$$
c_{n} \leqq C_{15} n^{2-4 k}
$$

which together with the normalization of the $P_{n}$, the definition of the $\lambda_{n}$, and (22) implies

$$
\left\|\lambda_{n}\right\|_{[-1,1] /[-1 / 4,1 / 4]} \leqq C_{16} n^{2-4 k}
$$

(17) follows by means of Markov's inequality.

It remains to show the order of approximation results. We cannot use the standard quantitative Korovkin theorem as

$$
\omega_{[-1 / 2,1 / 2]}\left(g, n^{-1}\right) \neq 0\left(\omega_{[-1 / 4,1 / 4]}\left(f, n^{-1}\right)\right) ;
$$

at least not in general. However a related method is applicable.

Again let $n \geqq 2 k$. $t^{2 k} \lambda_{4 n-4 k}(t)$ is a polynomial of degree $4 n-2 k$. Therefore for $j=1, \cdots, k$

$$
M_{j}=\int_{-1}^{1} t^{2 j} \lambda_{4 n-4 k}(t) d t=2 \sum_{i=1}^{n} x_{i, 2 n}^{2 j} A_{i}(2 n) \lambda_{4 n-4 k}\left(x_{i, 2 n}\right) ;
$$

where the $A_{i}(2 n)$ are the weights of the Gaussian quadrature formula, exact for polynomials of degree $4 n-1$, with nodes at the zeros of the Legendre polynomial of degree $2 n$. Since $\lambda_{4 n-4 k}$ has zeros at $x_{k+1,2 n}, \cdots, x_{n, 2 n}$, 


$$
M_{j}=2 \sum_{i=1}^{k} x_{i, 2 n}^{2 j} A_{i}(2 n) \lambda_{4 n-4 k}\left(x_{i, 2 n}\right)
$$

Since also $\lambda_{4 n-4 k}$ has a local maximum on $\left[-x_{k+1,2 n}, x_{k+1,2 n}\right]$ at zero, and Szego $[6$, p. 350]

$$
A_{i}(2 n) \leqq \frac{\pi}{2 n}(1+o(1)) \quad(i=1, \cdots, k),
$$

(22), (25) and the definition of the $\lambda_{n}$ imply

$$
\int_{-1}^{1} t^{2 j} \lambda_{n}(t) d t \leqq C_{17} n^{-2 j}, \quad j=1, \cdots, k ; n \geqq k .
$$

(26) and (17) may be used to estimate certain quantities involving $L_{n}^{*}$. All the estimates are uniform in $|x| \leqq 1 / 4$.

$$
\begin{aligned}
1-L_{n}^{*}(1, x) & =\int_{-1}^{1} \lambda_{n}(t) d t-\int_{-1 / 2-x}^{1 / 2-x} \lambda_{n}(t) d t \\
& \leqq 2 \int_{1 / 4}^{1} \lambda_{n}(t) d t \leqq C_{18} n^{2-4 k} . \\
L_{n}^{*}\left((t-x)^{2 j}, x\right) & =\int_{-1 / 2}^{1 / 2}(t-x)^{2 j} \lambda_{n}(t-x) d t \\
& =\int_{-1 / 2-x}^{1 / 2-x} t^{2 j} \lambda_{n}(t) d t \\
& \leqq \int_{-1}^{1} t^{2 j} \lambda_{n}(t) d t
\end{aligned}
$$

and applying (26)

$$
\begin{aligned}
L_{n}^{*}\left((t-x)^{2 j}, x\right) & \leqq C_{19} n^{-2 j}, \quad j=1, \cdots, k \\
L_{n}^{*}\left(|t-x|^{k}, x\right) & \leqq \int_{-1}^{1}|t|^{k} \lambda_{n}(t) d t \\
& \leqq\left[\int_{-1}^{1} t^{2 k} \lambda_{n}(t) d t\right]^{1 / 2} \\
& \leqq C_{20} n^{-k},
\end{aligned}
$$

where we have used the Schwartz inequality, (16) and (28).

For $j$ odd,

$$
\begin{aligned}
\left|L_{n}^{*}\left((t-x)^{j}, x\right)\right| & =\left|\int_{-1 / 2-x}^{1 / 2-x} t^{j} \lambda_{n}(t) d t\right| \\
& \leqq 2 \int_{1 / 4}^{1} t^{j} \lambda_{n}(t) d t
\end{aligned}
$$

since $\lambda_{n}$ is even. Applying (17)

$$
\left|L_{n}^{*}\left((t-x)^{j}, x\right)\right| \leqq C_{21} n^{2-4 k}, \quad j=1,3,5, \cdots .
$$


If $t \in[-1 / 2,1 / 2]$ and $x \in[-1 / 4,1 / 4]$, Taylor's theorem gives

$$
g(t)=\left[\sum_{j=0}^{k-1} \frac{g^{(j)}(x)(t-x)^{j}}{j !}\right]+\frac{1}{(k-1) !} \int_{x}^{t} g^{(k)}(u)(t-u)^{k-1} d u
$$

Since the last term on the right hand side is bounded in modulus by $(1 / k !)|\cdot t-x|^{k}\left\|g^{(k)}\right\|_{[-1 / 2,1 / 2]}$,

$$
\begin{aligned}
\left|L_{n}^{*}(g, x)-g(x)\right| \leqq & |g(x)|\left|1-L_{n}^{*}(1)\right|+\sum_{j=1}^{k-1} \frac{\left|g^{(j)}(x)\right|}{j !}\left|L_{n}^{*}\left((t-x)^{j}, x\right)\right| \\
& +\frac{1}{k !}\left\|g^{(k)}\right\|_{[-1 / 2,1 / 2]} L_{n}^{*}\left(|t-x|^{k}, x\right) .
\end{aligned}
$$

Thus

$$
\begin{aligned}
\left\|L_{n}^{*}(g, x)-g(x)\right\|_{[-1 / 4,1 / 4]} \leqq & \|g\|_{[-1 / 4,1 / 4]}\left\|1-L_{n}^{*}(1)\right\|_{[-1 / 4,1 / 4]} \\
& +\sum_{j=1}^{k-1} \frac{\left\|g^{(j)}\right\|_{[-1 / 4,1 / 4]}\left\|L_{n}^{*}\left((t-x)^{j}, x\right)\right\|_{[-1 / 4,1 / 4]}}{j !} \\
& +\frac{1}{k !}\left\|g^{(k)}\right\|_{[-1 / 2,1,2]}\left\|L_{n}^{*}\left(|t-x|^{k}, x\right)\right\|_{[-1 / 4,1 / 4]} .
\end{aligned}
$$

Combining the above, the estimates of all the terms involving $g$ from Lemma $1\left(g=L_{n}(f)\right.$, and the estimates (27), (28), (29), (30) of all the $L_{n}^{*}(\cdot, \cdot)$ yields $(19),(20)$.

Given Lemmas 1 and 2 it remains to discuss how close $L_{n}^{*}(g)$ is to a polynomial with nonnegative $k$ th derivative on $[-1 / 4,1 / 4]$.

THEOREM. For each $k \geqq 2$ there exists a constant $D_{k}$, such that for all $h \in C[-1 / 4,1 / 4]$ with kth difference nonnegative on $[-1 / 4,1 / 4]$

$$
E_{n, k}(h) \leqq D_{k} \omega_{[-1 / 4,1 / 4]}\left(h, n^{-1}\right), \quad n=k, k+1, \cdots .
$$

If in addition $h^{\prime} \in C[-1 / 4,1 / 4]$ then

$$
E_{n, k}(h) \leqq D_{k} n^{-1} \omega_{[-1 / 4,1 / 4]}\left(h^{\prime}, n^{-1}\right), \quad n=k, k+1, \cdots .
$$

Proof. Fix $k \geqq 2$. Let $f=h-\rho$ where

$$
\rho(x)=h\left(-\frac{1}{4}\right)+2\left(h\left(\frac{1}{4}\right)-h\left(-\frac{1}{4}\right)\right)\left(x+\frac{1}{4}\right) .
$$

Clearly $\omega\left(f, n^{-1}\right) \leqq 2 \omega\left(h, n^{-1}\right)$ and when $h^{\prime}$ exists $\omega\left(f^{\prime}, n^{-1}\right)=\omega\left(h^{\prime}, n^{-1}\right)$. Lemmas 1 and 2 apply to $f$. Writing

$$
\bar{L}_{n}(h)=\rho(x)+L_{n}^{*}\left(L_{n}(f)\right)
$$




$$
\begin{aligned}
\left\|h-\bar{L}_{n}(h)\right\|_{1 / 4} & =\left\|f-L_{n}^{*}\left(L_{n}(f)\right)\right\| \\
& \leqq\left\|f-L_{n}(f)\right\|_{1 / 4}+\left\|L_{n}(f)-L_{n}^{*}\left(L_{n}(f)\right)\right\|_{1 / 4} \\
& \leqq \begin{array}{ll}
C_{22} \omega\left(h, n^{-1}\right) & h \in C\left[-\frac{1}{4}, \frac{1}{4}\right] \\
C_{22} n^{-1} \omega\left(h^{\prime}, n^{-1}\right), & h^{\prime} \in C\left[-\frac{1}{4}, \frac{1}{4}\right]
\end{array}
\end{aligned}
$$

Let $g=L_{n}(f)$. Then

$$
\begin{aligned}
& \bar{L}_{n}(h)=\rho(x)+L_{n}^{*}(g)=\rho(x)+\int_{-1 / 2}^{1 / 2} g(t) \lambda_{n}(t-x) d t, \\
& \bar{L}_{n}(h, x)^{\prime}=\rho^{\prime}(x)+\int_{-1 / 2}^{1 / 2} g(t) \cdot-\lambda_{n}^{\prime}(t-x) d t \\
& =\rho^{\prime}(x)+\left[-g(t) \lambda_{n}(t-x)\right]_{-1 / 2}^{1 / 2}+\int_{-1 / 2}^{1 / 2} g^{\prime}(t) \lambda_{n}(t-x) d t .
\end{aligned}
$$

$k \geqq 2$ alternate differentiations and integrations by parts yield;

$$
\begin{aligned}
\bar{L}_{n}(h, x)^{(k)}= & (-1)^{k}\left[\sum_{j=0}^{k-1}(-1)^{j}\left[g^{(j)}(t) \lambda_{n}^{(k-1-j)}(t-x)\right]_{t=-1 / 2}^{t=1 / 2}\right] \\
& +\int_{-1 / 2}^{1 / 2} g^{(k)}(t) \lambda_{n}(t-x) d t \\
= & r(x)+\int_{-1 / 2}^{1 / 2} g^{(k)}(t) \lambda_{n}(t-x) d t .
\end{aligned}
$$

(5) and the positivity of the kernels imply the second term on the right hand side is nonnegative. Lemma 1 implies

$$
\left\|g^{(j)}\right\|_{1 / 2} \leqq C_{23} n^{k} \omega\left(h, n^{-1}\right), \quad j=0, \cdots, k-1, h \in C,\left[-\frac{1}{4}, \frac{1}{4}\right] .
$$

Hence using (17)

$$
\|v\|_{1 / 4} \leqq C_{24} n^{-k} \omega\left(h, n^{-1}\right)
$$

Let

$$
p_{n}(x)=\bar{L}_{n}(h, x)+\frac{x^{k}}{k !} C_{29} n^{-k} \omega\left(h, n^{-1}\right)
$$

$p_{n}^{(k)}(x)$ is nonnegative on $[-1 / 4,1 / 4]$, and by (32) $p_{n}$ provides the first estimate of the theorem. Similarly, when $h^{\prime} \in C[-1 / 4,1 / 4]$

$$
p_{n}(x)=\bar{L}_{n}(h, x)+\frac{x^{k}}{k !} C_{25} n^{-k-1} \omega\left(h^{\prime}, n^{-1}\right)
$$

provides the second estimate of the theorem. 


\section{REFERENCES}

1. P. J. Davis, Interpolation and Approximation, Blaisdell, N.Y., 1963.

2. R. A. DeVore, The Approximation of Continuous Functions by Positive Linear Operators, Lecture Notes in Mathematics \#293, Springer, 1972.

3. - Degree of Monotone Approximation, Linear Operators and Approximation 11, editors P. L. Butzer and B. Sz.-Nagy, Birkhauser Verlag, Stuttgart, 1974, 337-351.

4. G. G. Lorentz and K. L. Zeller, Degree of approximation by monotone polynomials 1, J. Approximation Theory, 1 (1968), 501-504.

5. G. G. Lorentz, Monotone Approximation, Inequalities 111, O. Shisha editor, Academic Press, New York, 1972, 201-215.

6. G. Szego, Orthogonal Polynomials, Amer. Math. Soc. Coll. Publ. Vol. XXIII, N. Y., 1959.

Received April 28, 1977.

UNIVERSITY OF CANTERBURY

Christchurch, New Zealand 


\section{PACIFIC JOURNAL OF MATHEMATICS}

\section{EDITORS}

RICHARD ARENS (Managing Editor)

University of California

Los Angeles, California 90024

C. W. Curtis

University of Oregon

Eugene, OR 97403

C. C. MOORE

University of California

Berkeley, CA 94720

\section{J. DUGUNDJI}

Department of Mathematics University of Southern California Los Angeles, California 90007

R. Finn AND J. Milgram Stanford University Stanford, California 94305

ASSOCIATE EDITORS
E. F. BECKENBACH

B. H. NeUMANN

F. WOLF

K. YoshidA

\section{SUPPORTING INSTITUTIONS}

UNIVERSITY OF BRITISH COLUMBIA UNIVERSITY OF SOUTHERN CALIFORNIA CALIFORNIA INSTITUTE OF TECHNOLOGY STANFORD UNIVERSITY UNIVERSITY OF CALIFORNIA MONTANA STATE UNIVERSITY UNIVERSITY OF TOKYO UNIVERSITY OF NEVADA, RENO UNIVERSITY OF UTAH NEW MEXICO STATE UNIVERSITY OREGON STATE UNIVERSITY UNIVERSITY OF OREGON

WASHINGTON STATE UNIVERSITY UNIVERSITY OF WASHINGTON OSAKA UNIVERSITY 


\section{Pacific Journal of Mathematics}

\section{Vol. 74, No. $1 \quad$ May, 1978}

Gerald Arthur Anderson, Computation of the surgery obstruction groups

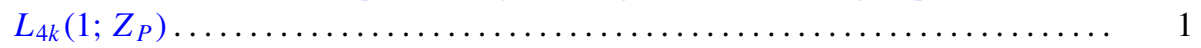

R. K. Beatson, The degree of monotone approximation ................ 5

Sterling K. Berberian, The character space of the algebra of regulated functions . . . 15

Douglas Michael Campbell and Jack Wayne Lamoreaux, Continua in the plane with

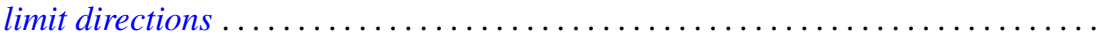

R. J. Duffin, Algorithms for localizing roots of a polynomial and the Pisot

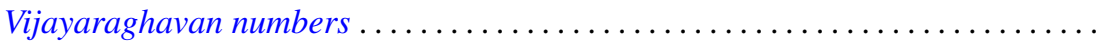

Alessandro Figà-Talamanca and Massimo A. Picardello, Functions that operate on

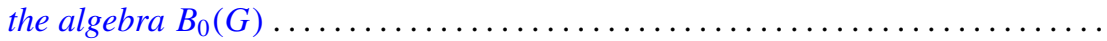

John Erik Fornaess, Biholomorphic mappings between weakly pseudoconvex

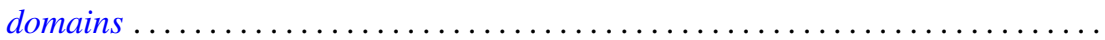

Andrzej Granas, Ronald Bernard Guenther and John Walter Lee, On a theorem of S.

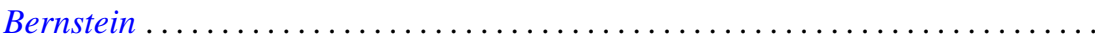

Jerry Grossman, On groups with specified lower central series quotients . .........

William H. Julian, Ray Mines, III and Fred Richman, Algebraic numbers, a constructive development . . . . . . . . . . . . . . . . . . . . . . .

Surjit Singh Khurana, A note on Radon-Nikodým theorem for finitely additive

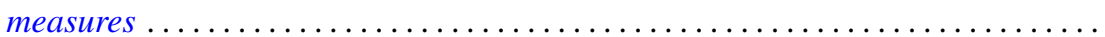

Garo K. Kiremidjian, A Nash-Moser-type implicit function theorem and nonlinear

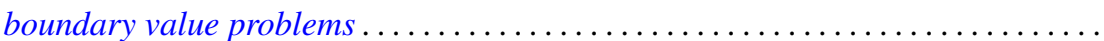

Ronald Jacob Leach, Coefficient estimates for certain multivalent functions ....

John Alan MacBain, Local and global bifurcation from normal eigenvalues. II . . 133

James A. MacDougall and Lowell G. Sweet, Three dimensional homogeneous algebras...

John Rowlay Martin, Fixed point sets of Peano continua ......

R. Daniel Mauldin, The boundedness of the Cantor-Bendixson order of some analytic sets...

Richard C. Metzler, Uniqueness of extensions of positive linear functions ..

Rodney V. Nillsen, Moment sequences obtained from restricted powers . .

Keiji Nishioka, Transcendental constants over the coefficient fields in differential elliptic function fields...

Gabriel Michael Miller Obi, An algebraic closed graph theorem

Richard Cranston Randell, Quotients of complete intersections by $\mathbf{C}^{*}$ actions . . 221

Bruce Reznick, Banach spaces which satisfy linear identities . .

Bennett Setzer, Elliptic curves over complex quadratic fields...

Arne Stray, A scheme for approximating bounded analytic functions on certain subsets of the unit disc.

Nicholas Th. Varopoulos, A remark on functions of bounded mean oscillation and bounded harmonic functions. Addendum to: "BMO functions and the

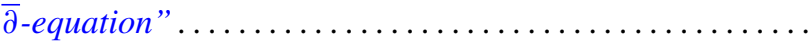

Charles Irvin Vinsonhaler, Torsion free abelian groups quasi-projective over their

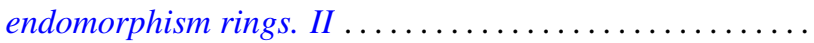

Thomas R. Wolf, Characters of $p^{\prime}$-degree in solvable groups ... 